\title{
Snow and Rain Modify Neighbourhood Walkability for Older Adults*
}

\author{
Philippa Clarke, ${ }^{1}$ Jana A. Hirsch, ${ }^{2}$ Robert Melendez, ${ }^{3}$ Meghan Winters, ${ }^{4}$ Joanie Sims Gould, ${ }^{5}$ \\ Maureen Ashe, ${ }^{5}$ Sarah Furst, ${ }^{6}$ and Heather McKay ${ }^{5}$
}

\begin{abstract}
RÉSUMÉ
La littérature a documenté une relation positive entre la mobilité à l'extérieur chez les personnes âgées et les environnements bâtisables et marchables. Cependant, étonnamment, toute considération de la façon dont le temps modifie l'accessibilité piétonnière à travers les quartiers est absente. À Vancouver, au Canada, on a utilisé des données météorologiques archivées liées à des données recueillies auprès d'un échantillon d'aînés. On a constaté que, lorsqu'il neige, les quartiers où l'on dépend d'automobiles (comportant des blocs plus longs, moins d'intersections et une plus grande distance aux commodités) sont devenus inaccessibles. Même les adultes plus âgés qui vivaient dans les quartiers qui étaient très bien adaptés au traffic pietonnier marchait à 25 pour cent moins de destinations pendant la neige. Il est essentiel de tenir compte de l'impact des conditions météorologiques dans la relation entre la marchabilité des quartiers et la mobilité des personnes âgées.
\end{abstract}

\begin{abstract}
The literature has documented a positive relationship between walkable built environments and outdoor mobility in older adults. Yet, surprisingly absent is any consideration of how weather conditions modify the impact of neighbourhood walkability. Using archived weather data linked to survey data collected from a sample of older adults in Vancouver, Canada, we found that car-dependent neighbourhoods (featuring longer block lengths, fewer intersections, and greater distance to amenities) became inaccessible in snow. Even older adults who lived in very walkable neighbourhoods walked to 25 per cent fewer destinations in snow. It is crucial to consider the impact of weather in the relationship between neighbourhood walkability and older adult mobility.
\end{abstract}

1 Institute for Social Research, Department of Epidemiology, University of Michigan

2 Carolina Population Center, University of North Carolina at Chapel Hill

3 Institute for Social Research, University of Michigan

4 Faculty of Health Sciences, Simon Fraser University

5 Centre for Hip Health and Mobility and Department of Family Practice, University of British Columbia

6 Centre for Hip Health and Mobility, University of British Columbia

* This research was supported by the Canadian Institutes of Health Research (CIHR) grant 117651, AAM-108607. Jana Hirsch received support from the Population Research Training grant (T32 HD007168) and the Population Research Infrastructure Program (R24 HD050924) awarded to the Carolina Population Center at The University of North Carolina at Chapel Hill by the Eunice Kennedy Shriver National Institute of Child Health and Human Development. Career award support for Maureen Ashe came from the CIHR and the Michael Smith Foundation for Health Research.

Manuscript received: / manuscrit reçu : 05/10/15

Manuscript accepted: / manuscrit accepté : 14/07/16

Mots clés : vieillissement, mobilité, quartier, mobilité, marchabilité, météo, neige

Keywords: aging, mobility, neighbourhood, walkability, weather, snow

La correspondance et les demandes de tire-à-part doivent être adressées à : / Correspondence and requests for offprints should be sent to:

Philippa J. Clarke, Ph.D.

Institute for Social Research

University of Michigan

426 Thompson Street

Ann Arbor, MI 48104

<pjclarke@umich.edu> 
Mobility, defined as an individual's ability to move about effectively in his or her surroundings (Patla \& Shumway-Cook, 1999; Webber, Porter, \& Menec, 2010), is vital for the independence, quality of life, and survival of older adults (Hirvensalo, Rantanen, \& Heikkinen, 2000; Rantakokko et al., 2010; Simonsick, Guralnik, Volpato, Balfour, \& Fried, 2005). Difficulty with mobility is highly prevalent in older adult populations, with negative consequences for physical function, participation in daily activities, and social connectedness (Fried, Bandeen-Roche, Chaves, \& Johnson, 2000; Guralnik, 1993; Guralnik, Ferrucci, Simonsick, Salive, \& Wallace, 1995). In short, maintaining mobility is considered by the World Health Organization (WHO) to be the best guarantee of retaining independence with aging (WHO, 1998).

Recent models of mobility (WHO, 2001; Verbrugge \& Jette, 1994; Webber et al., 2010) have drawn attention to environmental factors, such as characteristics in local built environments (Health Canada, 2002; Srinivasan, O'Fallon, \& Dearry, 2003), that interact with underlying impairments and physical capacity to impede or enhance a person's non-motorized outdoor mobility. A growing body of literature has documented a positive relationship between accessible built environments and outdoor mobility in older adults (Frank, Kerr, Rosenberg, \& King, 2010; Gauvin et al., 2012; King et al., 2011; Rosso, Auchincloss, \& Michael, 2011). In particular, more "walkable" neighbourhoods (i.e., those with greater land use mix, shorter block length, and greater street connectivity) have been associated with greater mobility among older persons (Clarke, Ailshire, Bader, Morenoff, \& House, 2008; Gallagher et al., 2010; King et al., 2000; King et al., 2005; Li et al., 2008; Michael, Beard, Choi, Farquhar, \& Carlson, 2006; Nagel, Carlson, Bosworth, \& Michael, 2008; Patterson \& Chapman, 2004; Rodríguez, Evenson, Diez Roux, \& Brines, 2009). Conversely, living in a neighbourhood without continuous sidewalks, designated crosswalks, or connected streets has been shown to be associated with reduced mobility (Clarke, Ailshire, Bader, Morenoff, \& House, 2008; Gallagher et al., 2012) and a greater risk of outdoor falls (Berg, Alessio, Mills, \& Tong, 1997; Li et al., 2006). Older adults with lower extremity impairment have also been shown to experience mobility challenges on grassy terrain and when carrying heavy packages over long distances (ShumwayCook et al., 2003).

Yet, surprisingly absent from this literature is any consideration of the impact of local weather on mobility. Specifically, we do not know how different weather conditions modify the impact of neighbourhood walkability on older adult mobility. Each year, some of North America's major cities (including Boston, Detroit, Cleveland, and Minneapolis) receive an average of over one meter (3.3 feet) of snow and have snow on the ground for more than three months. Icy surfaces, snow banks, and snowy/slushy surfaces are the most frequently named barriers to mobility among pedestrians during winter, particularly those with underlying limitations in physical functioning ( $\mathrm{Li}, \mathrm{Hsu}$, \& Fernie, 2010; Ryser \& Halseth, 2008). More than 37 per cent of older adults in Toronto, Canada, reduced their outdoor walking during the winter when they expected slippery sidewalk conditions (Li, Hsu, \& Fernie, 2013). Similarly, older adults in Detroit, Michigan, reported that a fear of falling on ice, sidewalks not cleared of snow and ice, and cold and rainy weather discouraged walking outdoors (Gallagher et al., 2010). A lack of shelters at public transit stops and decreased daylight hours during the winter months can also restrict mobility (Gallagher et al., 2010).

Thus, a neighbourhood that is somewhat walkable in summer months may become treacherous in winter, especially if uneven sidewalks are obscured by snow cover or if heavy rain makes cracks and uneven sidewalks difficult to distinguish. Further, a dirt or grass path may be navigable in dry weather, but is likely to become slippery when it rains. To counter these challenges, installing curb cuts at designated crosswalks may facilitate safe street crossings in places where older adults move more slowly or have difficulty stepping off the curb. However, if rain or snow accumulates at intersections to create puddles or snowbanks, this renders even designated "safe" crossings difficult to navigate. Older adults who rely on assistive devices for mobility (e.g., canes, walkers, wheelchairs, scooters) are even more vulnerable. For example, snow lodged in wheeled mobility devices forms an obstacle in the wheels and drive mechanisms and decreases the slip resistance of motorized scooters (Tadano, Tsukada, Shibano, Ukai, \& Watanuki, 1998).

It is not possible, therefore, to comprehensively understand the relationship between neighbourhood built environments and mobility without considering the impact of weather. The current lack of knowledge about how the walkability of different built environments varies or changes in different weather conditions prevents a more complete understanding of older adult mobility. To overcome these limitations, we examined the impact of weather-related factors on mobility across older adults living in neighbourhoods with various degrees of walkability. We used archived weather data linked to survey data collected from a sample of low-income community-dwelling older adults in Vancouver, British Columbia (BC). Vancouver is one of Canada's largest cities, with a moderate, oceanic climate. Although Vancouver is one of the wettest Canadian cities, receiving over $1,200 \mathrm{~mm}$ of rain per year on average, it also receives a non-trivial amount of snow 
(averaging 10.4-13.3 cm/month from December through February) (Environment Canada, n.d.). Both of these weather patterns cause slippery conditions and compromise mobility for Metro Vancouver's sizable elderly population. We hypothesized that snow and rain would restrict older adults' outdoor mobility, and that the mobility benefits of living in a walkable neighbourhood would be attenuated in rain and snow.

\section{Methods}

\section{Data}

Participants were recruited to take part in Walk the Talk (WTT), a cross-sectional study designed to investigate the association between the built environment and the mobility and health of low-income older adults (Chudyk et al., 2015). Participants resided in eight cities in Metropolitan Vancouver (Burnaby, New Westminster, North Vancouver, Richmond, Surrey, Vancouver, West Vancouver, and White Rock). The WTT sampling frame consisted of 5,806 households that receive a Shelter Aid for Elderly Renters (SAFER) rental subsidy from BC Housing, had a head of household aged 65 or older, and a telephone number on file with BC Housing. Households were sampled using a stratified random design, randomly selecting 200 households from within each decile of Walk Score (Front Seat Management, LLC; www.walkscore.com $)\left(n_{\text {total }}=2,000\right)$ to ensure that participants were recruited across a range of built environments.

Following a mailed letter introducing the study, all 2,000 households in the sampling frame were contacted via telephone between January and February 2012 to screen for eligibility. Of 1,319 individuals successfully contacted, $334(25 \%)$ were not eligible to participate as a result of study exclusion criteria (i.e., diagnosed with dementia; left their home less than once in a typical week; unable to understand or speak English; unable to walk more than 10 meters with or without a mobility aid; unable to participate in a mobility assessment involving a four meter walk). Of the 985 eligible subjects, 161 agreed to participate (706 were not interested; 118 declined for health reasons), resulting in a 16 per cent response rate (which is comparable to other telephone surveys with older adults [Kohut, Keeter, Doherty, Dimock, \& Christian, 2012] [King et al., 2011; Rosso, Grubesic, Auchincloss, Tabb, \& Michael, 2013]). There were no differences between participants and nonparticipants with respect to gender, but those who agreed to participate were slightly younger than those who did not (mean age of 74 vs. 77 years respectively).

All study participants were invited to an in-person measurement session at local community centres between February and December 2012 to collect objective measures of physical and cognitive function (transportation was provided to and from sessions); 70 per cent of these assessments were conducted between February and March, 10 per cent between April and May, 15 per cent between June and September, and 5 per cent in December. Participants were then asked to complete a self-administered survey at home that asked detailed questions about sociodemographic characteristics and outdoor mobility activities. The surveys were subsequently collected via a courier service so as not to inconvenience participants with "mail ins" or "drop offs". The University of British Columbia's Clinical Research Ethics Board (certificate H10-02913) approved the procedures used in the study.

\section{Measures}

The key dependent variable, outdoor mobility, was assessed in the self-administered questionnaire using items from the Neighbourhood Environment Walkability Survey (NEWS) (Saelens, Sallis, Black, \& Chen, 2003), which asks whether respondents walked to 26 different destinations in the past 30 days (including convenience store, supermarket, hardware store, fruit/vegetable market, dry cleaners, clothing store, post office, library, elementary school, other school, book store, restaurants, coffee shop, bank, video store, fast food place, pharmacy, hair salon, work/volunteer, bus or train stop, park, recreation centre, fitness facility, senior centre, health care clinic, bakery). We created a count of the total number of different destinations participants walked to in the past 30 days to capture the breadth of outdoor walking trips for day-to-day life activities that older adults may undertake within their local community.

Key independent variables included neighbourhood walkability, assessed objectively using Street Smart Walk Score (Front Seat Management, LLC). This single measure accounts for walkable street design (intersection density and block length) and network distance to popular amenities. We categorized walkability into four categories based on cut-off scores recommended by developers of Street Smart Walk Score (car dependent, 0-49; somewhat walkable, 50-69; very walkable, 70-89; and walker's paradise, 90-100). Walk Score was linked to each participant's residential address to get a score for their local neighbourhood (capturing features of the area within a one-quarter mile radius of that residential address).

Information about local weather was obtained from Weather Underground based on the Vancouver International Airport weather station (http://www. wunderground.com/history/airport/CYVR/). We downloaded daily weather data for 2012 (corresponding to the time frame when mobility data were gathered from study participants) and linked weather conditions in the past 30 days to each participant based 
on the date of interview. We focused on measures of precipitation, which we considered most likely to influence mobility, and with these data determined (1) the amount of rainfall (total $\mathrm{mm}$ ), and (2) the proportion of days with any snow, both in the past 30 days. Due to a high correlation between temperature and precipitation, we could not include both in our statistical models. Thus, we purposely chose to focus primarily on the effects of precipitation.

Key co-variates include age (years), gender, race (White; non-White), Canadian born (vs. foreign born), education level (completed secondary school or less; some trade/technical school or college through completed trade/technical school or college diploma; some university or higher), marital status (single; married; widowed; separated or divorced), and whether participants had a vehicle at their disposal. Cognitive function was assessed with the Montreal Cognitive Assessment (MoCA) instrument, a reliable, rapid (10 minute) screening instrument to evaluate mild cognitive dysfunction (Nasreddine et al., 2005). The highest MoCA score possible is 30 points; a score of 26 or higher is considered normal. We measured functional capacity objectively using the Short Physical Performance Battery (SPPB) (Guralnik et al., 1994), a brief ( $<10$ minute), reliable, performance battery that assesses balance, gait speed, and lower limb strength and endurance. SPPB includes three tests: gait speed over a 3-meter course, standing balance, and time to rise from a chair five times. Each performance test is assigned a score from 0 to 4 (where 4 captures high performance). Scores are summed to create a composite score that ranges from 0 to 12 . Higher scores reflect better physical function. A score of less than 10 typically identifies a more physically impaired group (Gill, 2010).

\section{Statistical Analysis}

Our mobility variable is a count of the number of different destinations participants walked to in the past 30 days. Therefore, we used Poisson regression to model the logarithm of the expected number of destinations older people walked to as a function of a linear combination of the independent variables. Analyses began by examining the separate effects of neighbourhood walkability and weather conditions on mobility, adjusting for individual co-variates. We then examined the association between snow and mobility and whether it varied by neighbourhood walkability, controlling for rain. A final model examined the moderating effect of neighbourhood walkability on the relationship between rain and mobility, controlling for snow. Statistical significance was assessed with a two-tailed alpha of .05 and all models were estimated in Stata 12 (StataCorp LP, College Station, Texas).

\section{Results}

Table 1 describes the characteristics of the study sample, overall and by each category of neighbourhood walkability. On average, these 161 older adults were 74 years of age, and the majority (63\%) were female. Just under half $(46 \%)$ were foreign born and 77 per cent were White. Most participants were separated/divorced $(45 \%)$ or widowed $(31 \%)$, and about a third $(32 \%)$ had a high school education or less. Mean SPPB score was 9.7 (range 4-12), which reflects some impairment in lower extremity function in these older adults on average. Mean score on the cognitive assessment (MoCA) was 23 (range 11-29), indicating mild cognitive impairment in our sample. There were no statistically significant differences in the health and sociodemographic characteristics of participants living in neighbourhoods with different levels of walkability.

A third of the study participants lived in neighbourhoods that were very walkable (32\%) according to the Walk Score while 20 per cent lived in a walker's paradise. However, approximately half lived in areas that were only somewhat walkable $(29 \%)$ or car dependent $(19 \%)$. Just over half had access to a vehicle on a regular basis. Despite the variation in neighbourhood walkability, these older adults reported walking to more than eight destinations, on average, in the past month (Table 1). Weather over the study period (163.2 [ \pm 49.6 ] $\mathrm{mm}$ of rain per month) was typical for Metro Vancouver. In addition, snow fell on $5.7( \pm 5.5)$ per cent of days in the past month on average (equivalent to 1.5 days in the past 30 days).

Table 2 reports results from the Poisson regression analyses for the number of places participants walked to in the past 30 days. Model A presents the coefficients for the main effects of neighbourhood walkability and weather conditions, adjusting for individual co-variates. Because the Poisson model is an exponential model, we can interpret the coefficients by taking the antilog of the parameter estimates. There were notable gender differences with women walking to more destinations in the past 30 days than did men $(\beta=.207$, Model A, Table 2). Expressing this effect in terms of the percentage difference in the expected number of destinations $\left(100\left[e^{.207}-1\right]\right)$, on average, women walked to 23 per cent more destinations than did men in the past month. Access to a vehicle reduced the expected number of destinations walked to by 28 per cent $\left(\left[100\left(e^{-.328}-1\right)\right]=-28 \%\right)$. Older adults with greater physical capacity reported walking to a greater number of destinations. Specifically, for each unit increase in SPPB score, the number of places individuals walked to in the past month increased by 6 per cent. Cognitive capacity was not associated with the number of destinations older peopled walked to. 
Table 1: Characteristics of the study sample overall and by neighborhood walkability: Data from Walk the Talk Study, Vancouver, BC (2012)

\begin{tabular}{|c|c|c|c|c|c|}
\hline \multirow[b]{2}{*}{ Participant Characteristic } & \multirow{2}{*}{ 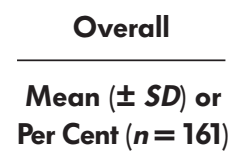 } & \multicolumn{4}{|c|}{ By Neighborhood Walkability (Street Smart Walk Score) } \\
\hline & & $\begin{array}{l}\text { Car Dependent } \\
\qquad(n=30)\end{array}$ & $\begin{array}{l}\text { Somewhat Walkable } \\
\qquad(n=46)\end{array}$ & $\begin{array}{l}\text { Very Walkable } \\
\qquad(n=53)\end{array}$ & $\begin{array}{l}\text { Walker's Paradise } \\
\qquad(n=32)\end{array}$ \\
\hline Age (range $65-96$ years) & $74.3(6.3)$ & $73.4(5.6)$ & $73.4(5.1)$ & $75.8(7.5)$ & $74.2(5.9)$ \\
\hline \multicolumn{6}{|l|}{ Gender } \\
\hline Female & 63.4 & 60.0 & 65.2 & 71.7 & 50.0 \\
\hline Non-White & 22.4 & 26.7 & 26.1 & 13.2 & 28.1 \\
\hline White & 77.6 & 73.3 & 73.9 & 86.8 & 71.9 \\
\hline \multicolumn{6}{|l|}{ Canadian born } \\
\hline Yes & 54.0 & 43.3 & 54.3 & 64.2 & 46.9 \\
\hline No & 46.0 & 56.7 & 45.7 & 35.8 & 53.1 \\
\hline \multicolumn{6}{|l|}{ Education } \\
\hline \multicolumn{6}{|l|}{ Marital Status } \\
\hline Single & 15.5 & 6.7 & 19.5 & 16.9 & 21.8 \\
\hline Married & 8.7 & 0.0 & 10.9 & 3.8 & 15.6 \\
\hline Widowed & 31.1 & 40.0 & 34.8 & 30.2 & 18.8 \\
\hline Separated/Divorced & 44.7 & 53.3 & 34.8 & 49.1 & 43.8 \\
\hline Physical Capacity (SPPB) (range 4-12) & $9.7(1.9)$ & $9.8(1.6)$ & $9.9(1.7)$ & $9.5(2.1)$ & $9.6(2.2)$ \\
\hline $\begin{array}{l}\text { Cognitive Capacity (MOCA) } \\
\text { (range 11-29) }\end{array}$ & $22.9(3.8)$ & $22.9(3.7)$ & $22.7(4.1)$ & $23.2(3.5)$ & $23.0(4.2)$ \\
\hline \multicolumn{6}{|l|}{ Access to a Vehicle } \\
\hline No & 46.6 & 30.0 & 42.2 & 52.8 & 56.2 \\
\hline Yes & 53.4 & 70.0 & 57.8 & 47.2 & 43.8 \\
\hline $\begin{array}{l}\text { Number of destinations walked to in } \\
\text { past } 30 \text { days (NEWS) }\end{array}$ & $8.8(6.0)$ & $4.1(4.4)$ & $6.9(5.3)$ & $11.0(5.4)$ & $12.3(5.5)$ \\
\hline
\end{tabular}

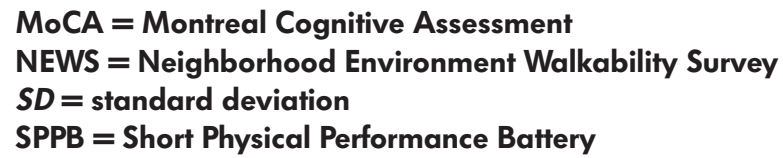

There were no significant relationships between any of the other sociodemographic or health characteristics and mobility. However, there were notable effects of neighbourhood walkability and weather conditions (Model A, Table 2). Older adults living in more walkable neighbourhoods (greater intersection density, shorter block length, more amenities) walked to more destinations in the past month. Compared to those living in car-dependent neighbourhoods, older adults living in neighbourhoods with the highest ranked Walk Scores (walker's paradise) walked to more than five additional destinations in the past month (211\% additional destinations, holding all other co-variates at their reference - null - values).

Conversely, snow had a negative effect on mobility. At average levels of rain (centered at the mean of $163 \mathrm{~mm}$ for analysis), a one per cent increase in the proportion of days with snow decreased the expected number of destinations older adults walked to in the past 30 days by a factor of $.24\left(e^{-1.437}=.24\right)$ or 76 per cent (Model A, Table 2). However, the adverse effects of snow on mobility varied depending on the walkability of the neighbourhood. Among older adults living in cardependent neighbourhoods snow was strongly and negatively associated with mobility (Model B, Table 2). A one per cent increase in the proportion of days with snow in the past month was associated with almost a 100 per cent reduction in the number of destinations older adults walked to in this period $\left(=100\left[e^{-9.779}-1\right]=-99.99 \%\right)$. However, this negative effect was attenuated in more walkable areas. In very walkable neighbourhoods, a one per cent increase in the proportion of days with snow decreased the expected number of places older adults walked to by only 25 per $\operatorname{cent}\left(=100\left[e^{-9.779+9.487=-.292}-1\right]=\right.$ $-25 \%$ ) (Model B, Table 2). These differences are illustrated in Figure 1. Note that residing in the most walkable neighbourhoods (walker's paradise) did 
Table 2: Poisson regression coefficients: Number of places walked to in past $\mathbf{3 0}$ days by neighbourhood walkability (Street Smart Walk Score) and weather conditions - Data from Walk the Talk Study in Vancouver, BC (n= 161) 2012

\begin{tabular}{|c|c|c|c|}
\hline & $\begin{array}{l}\text { Walk Score and Weather } \\
\text { Main Effects }\end{array}$ & $\begin{array}{l}\text { Interaction with Walk } \\
\text { Score and Snow }\end{array}$ & $\begin{array}{l}\text { Interaction with Walk } \\
\text { Score and Rain }\end{array}$ \\
\hline Independent Variable & Model A & Model B & Model C \\
\hline Intercept & .975 & $1.269 *$ & $1.655^{* *}$ \\
\hline White race & .071 & .110 & .105 \\
\hline Age & .001 & .001 & .002 \\
\hline \multicolumn{4}{|l|}{ Marital Status } \\
\hline Married & (ref) & (ref) & (ref) \\
\hline Single & -.192 & -.191 & -.157 \\
\hline Widowed & -.093 & -.075 & -.101 \\
\hline Separated/Divorced & .034 & .033 & .065 \\
\hline \multicolumn{4}{|l|}{ Education } \\
\hline Cognitive Capacity (MoCA) & -.010 & -.008 & -.008 \\
\hline Physical Capacity (SPPB) & $.058 * * *$ & $.054^{* *}$ & $.052^{* *}$ \\
\hline Rain - Total precipitation (mm) & .001 & $.001^{*}$ & $-.006^{* *}$ \\
\hline Snow -Proportion of days with snow & $-1.437^{* *}$ & $-9.779^{* *}$ & $-1.189^{*}$ \\
\hline \multicolumn{4}{|l|}{ Street Smart Walk Score } \\
\hline Car dependent & (ref) & (ref) & (ref) \\
\hline Somewhat walkable & $.535^{* * *}$ & $.155^{\prime}$ & $-1.004^{*}$ \\
\hline Very walkable & $.965^{* * *}$ & $.492^{* *}$ & .005 \\
\hline Walker's paradise & $1.136^{* * *}$ & $.833^{* * *}$ & .311 \\
\hline \multicolumn{4}{|l|}{ Snow $x$ Walk Score } \\
\hline Car dependent & & (ref) & \\
\hline Somewhat walkable & & $8.023^{*}$ & \\
\hline
\end{tabular}

${ }^{*} p<.05{ }^{* *} p<.01{ }^{* * *} p<.001$ (two-tailed tests)

MoCA = Montreal Cognitive Assessment

SPPB $=$ Short Physical Performance Battery

not confer the same protective benefits in snowy weather. In these areas, a one per cent increase in the proportion of days with snow reduced the expected number of destinations that older adults walked to by 95 per cent $\left(=100\left[e^{-9.779+6.861=-2.918}-1\right]=-95 \%\right)$ (Model B, Table 2).

In contrast, rain had less pronounced effects on mobility in our Vancouver sample of older adults. Rain had no significant main effect on the number of destinations older adults walked to in the past month (Model A, Table 2), but the effect varied across different built environments (Model C, Table 2). Specifically, among older adults who lived in car-dependent neighbourhoods, rain was negatively associated with mobility. Holding all other co-variates at their reference (null) values, an increase in $10 \mathrm{~mm}$ of rain in the past 30 days decreased the number of destinations older adults walked to in car-dependent neighbourhoods by a factor of $.94\left(e^{-.06}=.94\right)$ or by 6 per cent $\left(=100\left[e^{-.06}-1\right]=-6 \%\right)($ Model C, Table 2$)$. In contrast, for older adults who lived in very walkable or highly walkable (walker's paradise) neighbourhoods, rain had no significant effect on mobility. In a walker's paradise, the effect of $10 \mathrm{~mm}$ of rain had no impact on the number of destinations walked to $\left(=100\left[e^{-.06+.06}-1\right]=-0 \%\right)$, while in very walkable neighbourhoods the effect of $10 \mathrm{~mm}$ of rain had almost no impact $\left(=100\left[e^{-.06}+.07-1\right]=-1 \%\right)$. These differences are plotted in Figure 2. 


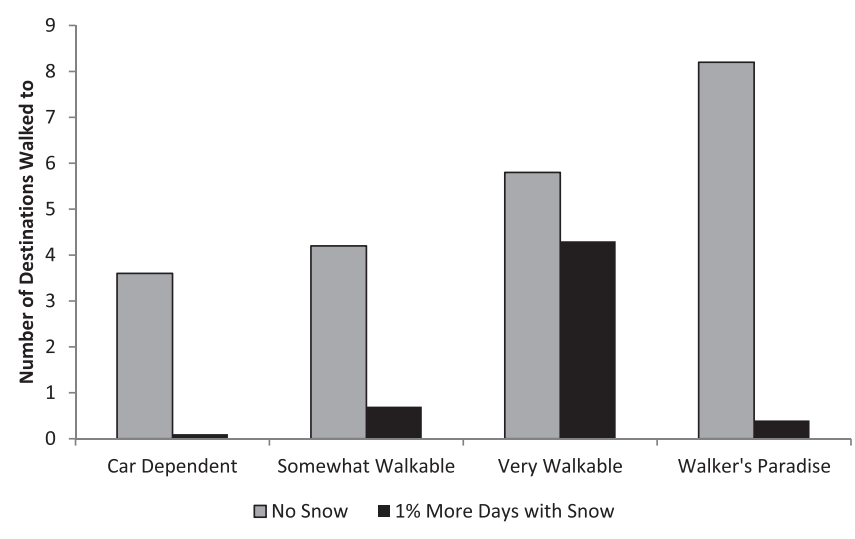

Figure 1: Predicted number destinations older adults walked to in past 30 days by neighbourhood walkability a and proportion of days with snow

a Neighbourhood walkability is based on categories of Street Smart Walk Score. The predicted number of destinations walked to - at average levels of rain - is calculated for a 65 -year-old non-White female, Canadian born, married, with secondary school education, without access to a vehicle, with average physical and cognitive capacity.

\section{Discussion}

We address current gaps in the knowledge base of older adult mobility by examining the role of weather conditions on the well-documented relationship between neighbourhood walkability and mobility. A key strength of our study was its focus on outdoor mobility in an under-studied, socioeconomically vulnerable population of community-dwelling older adults who were

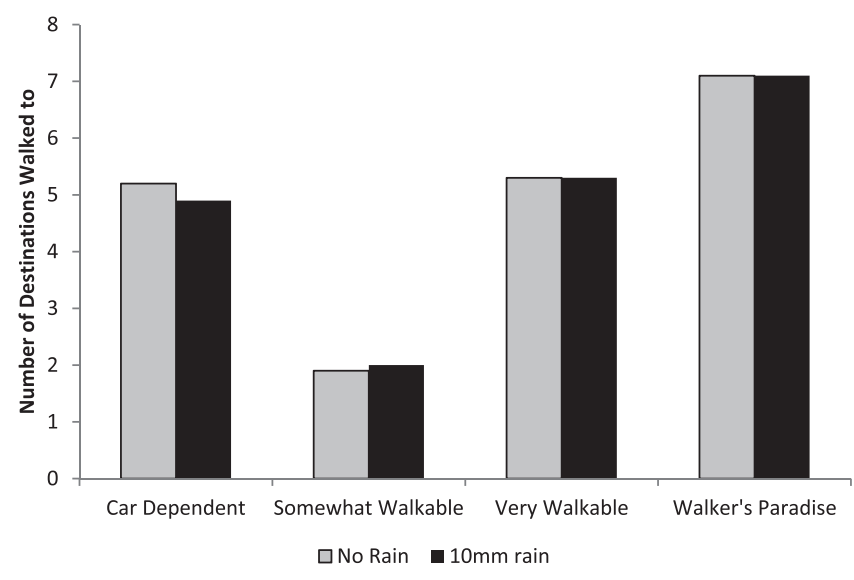

Figure 2: Predicted number destinations older adults walked to in past 30 days by neighbourhood walkability and total rainfall (millimetres)

\footnotetext{
a Neighbourhood walkability is based on categories of Street Smart Walk Score. The predicted number of destinations walked to is calculated for a 65-year-old non-White female, Canadian born, married, with secondary school education, without access to a vehicle, with average physical and cognitive capacity, with no snow in the past 30 days.
}

experiencing housing instability as well as physical and cognitive impairment. We found that those who lived in more walkable neighbourhoods walked to more destinations in the past month. This is consistent with studies of community-dwelling older adults of average income (Hirsch, Moore, Evenson, Rodriguez, \& Roux, 2013). However, we also found that weather conditions changed the degree to which walkable neighbourhoods were associated with mobility. Specifically, car-dependent neighbourhoods, characterized by longer block lengths, fewer intersections and greater distance to amenities, appeared to become almost inaccessible for older adults when there was snow. The predicted number of destinations that older residents walked to in these neighbourhoods decreased to almost zero when there was snow. Even older adults who lived in very walkable neighbourhoods walked to 25 per cent fewer destinations when there was snow. We did not find any interactions between snow and individual factors (physical or cognitive capacity, gender). However, women tended to walk to more destinations than men, and individuals with greater physical capacity tended to walk to more places than those who had reduced physical capacity. Not surprisingly, individuals with access to a motorized vehicle walked to fewer destinations in any given neighbourhood.

We were somewhat surprised by the negative effect of snow on mobility among those who lived in the most walkable neighbourhoods (walker's paradise according to the Street Smart Walk Score). This may reflect the density of nearby stores and restaurants in walkable environments, which may offer delivery services that minimize the need for older people to go out in inclement weather. This finding may also be due to unmeasured differences in individual socioeconomic resources among those who lived in very walkable neighbourhoods that afford these participants greater flexibility to choose not to go out in adverse weather. For example, an older person's decision to walk to the store when there is snow is likely dependent on financial (e.g., sufficient money to take a taxi) and human (e.g., someone else picks up groceries) resources that alone and together provide alternative options in the face of adverse weather. Although we found no difference in the health and sociodemographic characteristics of participants living in different neighbourhoods, measures of income and social support were not available in the data. Thus, we were unable to determine with our data whether those with access to greater economic resources and social support were more likely to live in the most walkable neighbourhoods. We therefore introduce this line of reasoning merely as one potential explanation for these apparently counterintuitive findings.

Rain was less of a barrier for mobility in these Vancouverdwelling older adults. Rain had no effect on the number 
of destinations people walked to on average, and only a small negative impact on mobility for those who lived in car-dependent neighbourhoods. Rain is not uncommon in Vancouver, and older adults are likely to have learned how to manage getting out and about in the rain (e.g., by wearing appropriate footwear or clothing). This is especially likely since the majority of participants were long-term residents of Vancouver (over 35 years on average) and, as such, have been exposed to rainy conditions over many years. Most notably, the adverse effects of rain on mobility were essentially non-existent in very or highly walkable neighbourhoods.

On the other hand, snow was clearly a problem for these Vancouver seniors. While snow may not stay on the ground for an extended period of time, older adults in Vancouver are less familiar with these conditions that can generate icy surfaces and subsequent problems for mobility (Li et al., 2013). Elsewhere, older Americans were also found to have twofold higher odds of reporting "a great deal of difficulty leaving home when icy" compared to younger adults (Clarke, Yan, Keusch, \& Gallagher, 2015).

Although it is not possible to change the weather, we can invest in the design of outdoor built environments to minimize the impact of adverse weather on older adult mobility. Our findings emphasize that the negative influence of both snow and rain on mobility is diminished in more walkable neighbourhoods. Walkable neighbourhoods host a greater density of nearby destinations that require shorter trips to reach amenities. Thus, even in bad weather, walking remains a feasible form of transport in these types of neighbourhoods.

Our findings have relevance regarding allocation of resources by municipalities since wide, continuous sidewalks promptly cleared of snow and ice facilitate outdoor mobility even during winter weather (Hanson et al., 2013). Li et al. (2013) argued for ensuring that ice and water do not build up at the base of curb cuts in winter weather, as this renders pedestrian crossings non-navigable for older adults. Municipalities might also consider alternative designs for curb cuts and pedestrian intersections that facilitate safe mobility for older adults in winter weather ( $\mathrm{Li}$ et al., 2013; Perry, 2014), even in the most walkable built environments.

Collectively, our results argue for the integration of weather conditions into studies of the built environment and mobility, and even into calculations of walkability indices more generally. Almost all studies of the built environment and mobility in older adults have been specific to single urban areas (e.g., Portland [Michael et al., 2009], Atlanta [Frank et al., 2010], Baltimore
[Glass, Rasmussen, \& Schwartz, 2006], Detroit [Gallagher et al., 2010]). This creates a gap in our knowledge regarding whether the association between key built environment features and mobility is unique to the weather or climate in specific regions. For example, a city neighbourhood considered very walkable in a hot, dry climate may not be as walkable in climates that experience more regular rain or snow. We also do not currently know how the relationship between key built environment factors, weather, and mobility is altered in small urban, rural, or remote communities.

Our study is not without limitations. The study sample was limited to a socioeconomically vulnerable population of older adults. However, our focus on this population could also be viewed as a strength because this is precisely the group most likely to be negatively affected by weather as they are less likely to own a car and have limited options for transportation. However, possibly in part because we were sampling from a vulnerable population of older adults, the participation rate in this study was low $(16 \%)$. Nonetheless, this is comparable to participation rates from other telephone surveys (Kohut et al., 2012) and surveys of older adult mobility (King et al., 2011; Rosso et al., 2013). Information on the different destinations people walked to was collected through a self-administered survey, and we did not have the opportunity to uncover the reasons why some destinations were not walked to, including the impact of weather-related factors. In addition, our measure of mobility was based on the total number of different places walked to in the past 30 days, not the total number of walking trips. Future work would benefit from the use of objective measures of mobility linked to weather conditions in real time. Data were also restricted to Metro Vancouver, which has a unique oceanic climate, and differences by geographic region are likely when considering the impact of weather on mobility (Clarke et al., 2015). However, given that weather restricted mobility even in a relatively mild Canadian climate like Vancouver, the impact could be of even greater magnitude for older adults living in regions with more severe or changeable weather conditions. We were not able to examine the effect of temperature on mobility over and above precipitation, given the strong collinearity between temperature and precipitation. However, in separate models, temperature had little effect on older adult mobility in this Vancouver sample. Data on the built environment were obtained using the Street Smart Walk Score, which relies on aggregate characteristics of block length, proximity to amenities, and intersection density to rate neighbourhood walkability. More detailed street features and pedestrian amenities (e.g., presence of curb cuts, bus shelters, trees, benches upon which to rest) would provide more information about built environment features 
that likely influence mobility in older adult populations. Finally, we were unable to model the effects of other personal factors, such as choice of footwear or balance problems, and we acknowledge that these could change older people's decision to walk in snow or rain.

To conclude, we highlight that it is crucial to consider weather conditions when examining mobility in older adults. Further research should consider how a range of different weather conditions modify the walkability of built environments and how living in more or less walkable urban, suburban, or rural neighbourhoods attenuates or intensifies the impact of inclement weather on older adult mobility. Town and city planners should be encouraged to build more walkable neighbourhoods that encourage older adults to maintain outdoor mobility and social interaction even in challenging weather conditions (Perry, 2014). It is not beyond the realm of possibility that neighbourhood walkability will become an important communitylevel coping tool that supports mobility in the very real face of climate change.

\section{References}

Berg, W. P., Alessio, H. M., Mills, E. M., \& Tong, C. (1997). Circumstances and consequences of falls in independent community-dwelling older adults. Age and Ageing, 26(4), 261-268.

Chudyk, A. M., Winters, M., Moniruzzaman, M., Ashe, M. C., Gould, J. S., \& McKay, H. (2015). Destinations matter: The association between where older adults live and their travel behavior. Journal of Transport \& Health, 2(1), 50-57.

Clarke, P., Ailshire, J. A., Bader, M., Morenoff, J. D., \& House, J. S. (2008). Mobility disability and the urban built environment. American Journal of Epidemiology, 168(5), 506-513.

Clarke, P. J., Yan, T., Keusch, F., \& Gallagher, N. A. (2015). The impact of weather on mobility and participation in older US adults. American Journal of Public Health, 105(7), 1489-1494.

Environment Canada. (n.d.). 1971-2000 climate normals \& averages. Retrieved from http:/ / climate.weather.gc.ca/ climate_normals/index_e.html

Frank, L., Kerr, J., Rosenberg, D., \& King, A. (2010). Healthy aging and where you live: Community design relationships with physical activity and body weight in older Americans. Journal of physical activity $\mathcal{E}$ health, 7(1), S82-S90.

Fried, L. P., Bandeen-Roche, K., Chaves, P. H. M., \& Johnson, B. A. (2000). Preclinical mobility disability predicts incident mobility disability in older women. The Journals of Gerontology Series A: Biological Sciences and Medical Sciences, 55(1), M43-M52.
Gallagher, N., Clarke, P., Loveland-Cherry, C., Ronis, D., Nyquist, L., \& Gretebeck, K. (2012). Environmental and psychosocial influences on neighborhood walking in older adults with and without mobility limitations. Research in Gerontological Nursing, 5, 238-250.

Gallagher, N., Gretebeck, K., Robinson, J., Torres, E., Murphy, S., \& Martyn, K. (2010). Neighborhood factors relevant for walking in older, urban, African American adults. Journal of Aging and Physical Activity, 18(1), 99-115.

Gauvin, L., Richard, L., Kestens, Y., Shatenstein, B., Daniel, M., Moore, S. D., ... Payette, H. (2012). Living in a wellserviced urban area is associated with maintenance of frequent walking among seniors in the VoisiNuAge study. The Journals of Gerontology Series B: Psychological Sciences and Social Sciences, 67B(1), 76-88. doi: https:/ / doi.org/10.1093/geronb/gbr134

Gill, T. M. (2010). Assessment of function and disability in longitudinal studies. Journal of the American Geriatrics Society, 58, S308-S312.

Glass, T. A., Rasmussen, M. D., \& Schwartz, B. S. (2006). Neighborhoods and obesity in older adults: The Baltimore memory study. American Journal of Preventive Medicine, 31(6), 455-463.

Guralnik, J. M. (1993). Maintaining mobility in late life. I. Demographic characteristics and chronic conditions. American Journal of Epidemiology, 137(8), 845-857.

Guralnik, J. M., Ferrucci, L., Simonsick, E. M., Salive, M. E., \& Wallace, R. B. (1995). Lower-extremity function in persons over the age of 70 years as a predictor of subsequent disability. The New England Journal of Medicine, 332(9), 556-561.

Guralnik, J. M., Simonsick, E. M., Ferrucci, L., Glynn, R. J., Berkman, L., Blazer, D. G., ... Wallace, R. B. (1994). A short physical performance battery assessing lower extremity function: association with self-reported disability and prediction of mortality and nursing home admission. Journal of Gerontology, 49(2), M85-M94.

Hanson, H. M., Schiller, C., Winters, M., Sims-Gould, J., Clarke, P., Curran, E., ... McKay, H. A. (2013). Concept mapping applied to the intersection between older adults' outdoor walking and the built and social environments. Preventive Medicine, 57(6), 785-791.

Health Canada, Division of Childhood and Adolescence. (2002). Natural and Built Environments. Ottawa, ON: Author.

Hirsch, J. A., Moore, K. A., Evenson, K. R., Rodriguez, D. A., \& Roux, A. V. D. (2013). Walk score ${ }^{\circledR}$ and transit score ${ }^{\circledR}$ and walking in the multi-ethnic study of atherosclerosis. American Journal of Preventive Medicine, 45(2), 158-166.

Hirvensalo, M., Rantanen, T., \& Heikkinen, E. (2000). Mobility difficulties and physical activity as predictors of mortality and loss of independence in the community-living older population. Journal of the American Geriatrics Society, 48(5), 493-498. 
King, A. C., Castro, C., Wilcox, S., Eyler, A. A., Sallis, J. F., \& Brownson, R. C. (2000). Personal and environmental factors associated with physical inactivity among different racial-ethnic groups of U.S. middle-aged and older-aged women. Health Psychology, 19(4), 354-364.

King, A. C., Sallis, J. F., Frank, L. D., Saelens, B. E., Cain, K., Conway, T. L., ... Kerr., J. (2011). Aging in neighborhoods differing in walkability and income: Associations with physical activity and obesity in older adults. Social Science $\mathcal{E}$ Medicine, 73(10), 1525-1533.

King, W. C., Belle, S. H., Brach, J. S., Simkin-Silverman, L. R., Soska, T., \& Kriska, A. M. (2005). Objective measures of neighborhood environment and physical activity in older women. American Journal of Preventive Medicine, 28(5), 461-469.

Kohut, A., Keeter, S., Doherty, C., Dimock, M., \& Christian, L. (2012). Assessing the representativeness of public opinion surveys. Washington, DC: Pew Research Center.

Li, F., Harmer, P. A., Cardinal, B. J., Bosworth, M., Acock, A., Johnson-Shelton, D., \& Moore, J. M. (2008). Built environment, adiposity, and physical activity in adults aged 50-75. American Journal of Preventive Medicine, 35(1), $38-46$.

Li, W., Keegan, T. H. M., Sternfeld, B., Sidney, S., Quesenberry, C. P., Jr., \& Kelsey, J. L. (2006). Outdoor falls among middle-aged and older adults: A neglected public health problem. American Journal of Public Health, 96(7), 1192-1200.

Li, Y., Hsu, J., \& Fernie, G. (2013). Aging and the use of pedestrian facilities in winter-The need for improved design and better technology. Journal of Urban Health, 90(4), 602-617.

Li, Y., Hsu, J., \& Fernie, G. R. (2010). Winter accessibility survey results: Inadequate consideration of weather elements in the development of pedestrian facilities. Gerontechnology, 9(2), 301.

Michael, Y., Beard, T., Choi, D., Farquhar, S., \& Carlson, N. (2006). Measuring the influence of built neighborhood environments on walking in older adults. Journal of Aging and Physical Activity, 14, 302-312.

Michael, Y. L., Keast, E. M., Chaudhury, H., Day, K., Mahmood, A., \& Sarte, A. F. I. (2009). Revising the senior walking environmental assessment tool. Preventive Medicine, 48(3), 247-249.

Nagel, C. L., Carlson, N. E., Bosworth, M., \& Michael, Y. L. (2008). The relation between neighborhood built environment and walking activity among older adults. American Journal of Epidemiology, 168(4), 461-468.

Nasreddine, Z. S., Phillips, N. A., Bédirian, V., Charbonneau, S., Whitehead, V., Collin, I., ... Chertkow, H. (2005). The Montreal Cognitive Assessment, MoCA: A brief screening tool for mild cognitive impairment. Journal of the American Geriatrics Society, 53(4), 695-699.
Patla, A., \& Shumway-Cook, A. (1999). Dimensions of mobility: Defining the complexity and difficulty associated with community mobility. Journal of Aging and Physical Activity, 7, 7-19.

Patterson, P. K., \& Chapman, N. J. (2004). Urban form and older residents' service use, walking, driving, quality of life, and neighborhood satisfaction. American Journal of Health Promotion, 19, 45-52.

Perry, T. E. (2014). Seasonal variation and homes: Understanding the social experiences of older adults. Care Management Journals, 15(1), 3-10.

Rantakokko, M., Iwarsson, S., Kauppinen, M., Leinonen, R., Heikkinen, E., \& Rantanen, T. (2010). Quality of life and barriers in the urban outdoor environment in old age. Journal of the American Geriatrics Society, 58(11), 2154-2159.

Rodríguez, D. A., Evenson, K. R., Diez Roux, A. V., \& Brines, S. J. (2009). Land use, residential density, and walking: The multi-ethnic study of atherosclerosis. American Journal of Preventive Medicine, 37(5), 397-404.

Rosso, A. L., Auchincloss, A. H., \& Michael, Y. L. (2011). The urban built environment and mobility in older adults: A comprehensive review. Journal of Aging Research, 2011, 10. doi: $10.4061 / 2011 / 816106$

Rosso, A. L., Grubesic, T. H., Auchincloss, A. H., Tabb, L. P., \& Michael, Y. L. (2013). Neighborhood amenities and mobility in older adults. American Journal of Epidemiology, 178(5), 761-769.

Ryser, L., \& Halseth, G. (2008). Institutional barriers to incorporating climate responsive design in commercial redevelopment. Environment and Planning B: Planning and Design, 35(1), 34-55.

Saelens, B. E., Sallis, J. F., Black, J. B., \& Chen, D. (2003). Neighborhood-based differences in physical activity: An environment scale evaluation. American Journal of Public Health, 93(9), 1552-1558.

Shumway-Cook, A., Patla, A., Stewart, A., Ferrucci, L., Ciol, M. A., \& Guralnik, J. M. (2003). Environmental components of mobility disability in community-living older persons. Journal of the American Geriatrics Society, 51(3), 393-398.

Simonsick, E. M., Guralnik, J. M., Volpato, S., Balfour, J., \& Fried, L. P. (2005). Just Get Out the Door! Importance of Walking Outside the Home for Maintaining Mobility: Findings from the Women's Health and Aging Study. Journal of the American Geriatrics Society, 53(2), 198-203.

Srinivasan, S., O'Fallon, L. R., \& Dearry, A. (2003). Creating healthy communities, healthy homes, healthy people: Initiating a research agenda on the built environment and public health. American Journal of Public Health, 93, 1446-1450.

Tadano, S., Tsukada, A., Shibano, J.-i., Ukai, T., \& Watanuki, Y. (1998). Driving tests and computer simulations of electric wheelchairs on snow-covered roads. JSME International 
Journal. Series C, Mechanical Systems, Machine Elements and Manufacturing, 41(1), 68-75.

Verbrugge, L. M., \& Jette, A. M. (1994). The disablement process. Social Science and Medicine, 38, 1-4.

Webber, S. C., Porter, M. M., \& Menec, V. H. (2010). Mobility in older adults: A comprehensive framework. The Gerontologist, 50(4), 443-450.
World Health Organization (1998). Life in the 21st centuryA vision for all. The World Health Report. Geneva, CHE: Author.

World Health Organization (2001). International Classification of Functioning, Disability and Health. Geneva, CHE. Author. Retrieved from http://www.who.int/classifications / icf/en/ 